\title{
A retrospective, observational study of medicolegal cases against obstetricians and gynaecologists in South Africa's private sector
}

\author{
B Taylor, MB ChB, Int Dip Res Ethics, MPH (Health Economics); S Cleary, BA, BA Hons, MA (Economics), PhD \\ Health Economics Unit, School of Public Health and Family Medicine, Faculty of Health Sciences, University of Cape Town, South Africa
}

Corresponding author: B Taylor (bettinataylor2@icloud.com)

Background. The viability of obstetric practice in the private sector has been threatened as a result of steep increases in professional indemnity fees over the past 10 years. Despite this, empirical research investigating key aetiological factors to target risk management interventions has been lacking.

Objectives. To explore private practice medicolegal data linked to obstetricians and gynaecologists (O\&Gs) to identify factors in clinical practice associated with claims, for the purposes of guiding future research and risk management solutions.

Methods. This was a retrospective, observational study of private sector O\&Gs' medicolegal case histories. All incidents declared to a prominent local professional indemnity insurer were categorised in terms of medicolegal case type, as well as clinical parameters. To allow for risk-adjusted calculations of case incidence, year of entry into private practice was estimated for all practitioners.

Results. Steep increases in medicolegal investigations and demands were demonstrated for both obstetrics- and gynaecology-related cases from about 2003 to 2012. Whereas the total numbers of claims, regulatory complaints and requests for records were similar for obstetrics and gynaecology in recent years (accounting for $52 \%$ v. $48 \%$ of known cases, respectively), a significantly greater percentage of demands and paid settlements related to gynaecology rather than obstetrics ( $58 \%$ and $76 \% \mathrm{v} .42 \%$ and $24 \%$ of cases, respectively). In obstetrics, about half of all cases on record with a paid settlement were in the context of severe neonatal birth-related neurological injury ( $n=9)$. For gynaecology, procedure-related complications accounted for $92 \%$ of settlements, of which at least $41 \%$ were for intraoperative injuries to internal organs and vessels. Laparoscopic procedures were most frequently associated with such intraoperative injuries, followed by vaginal and abdominal hysterectomies/oophorectomies and caesarean sections. For O\&Gs in private practice for $>2$ years, 50/458 (11\%) accounted for $138 / 228$ (61\%) of demands over a 10-year period.

Conclusions. The higher number of gynaecological demands and settlements in comparison with obstetric cases was unexpected and is contrary to international experiences and public sector findings, calling for more research to identify reasons for this finding. Other than further exploring surgical outcomes in private sector gynaecological patients, aspects of surgical training and accreditation standards in gynaecology may need review. Regarding birth-related injuries, the contribution of system failures needs quantification and further interrogation. The high contribution towards the medicolegal burden by a small group of practitioners suggests a need for doctor-focused interventions, including strengthening of peer review and regulatory oversight.

S Afr Med J 2021;111(7):661-667. https://doi.org/10.7196/SAMJ.2021.v111i7.15511

Claims for alleged medical negligence are a cause for concern in many parts of the world. Whereas a high frequency and escalating quantum of claims have typically been associated with developed countries such as the USA and Australia, ${ }^{[1]}$ similar patterns of claim increases have more recently also been described in less developed countries. In Taiwan, there has been a fourfold increase in civil claims against doctors between 2004 and 2007. ${ }^{[2]} \mathrm{Li}$ et al. ${ }^{[3]}$ refer to an 'unprecedented level' of disputes between patients and doctors in their review of medical malpractice litigation in China from 1998 to 2011. In South Africa (SA), contingent liabilities for alleged medical negligence by state facilities have increased exponentially over recent years, from ZAR56.96 billion in 2017 (D Bass, medicolegal head, Western Cape Department of Health, personal communication November 2017) to ZAR98 billion in $2019 .{ }^{[4]}$ In the private sector, the Medical Protection Society (MPS), a UK-based indemnifier of medical professionals, reported an increase in claims of 35\% between 2011 and 2016 and an increase in claim size by $>14 \%$ on average each year between 2009 and 2015 across its membership, which includes specialist groups, family practitioners, allied healthcare professionals and state employees. ${ }^{[5,6]}$
In both sectors, claims in relation to obstetrics have been identified as the predominant determinant of financial risk for indemnifiers. In 2017, 4 063/7 889 claims (52\%) against the state in SA were related to obstetrics and gynaecology (O\&G). Of these, $3089(76 \%)$ were for cases of cerebral palsy, accounting at ZAR36.633 billion for $94 \%$ of the demands made in terms of O\&G, or $64 \%$ of total demands (D Bass, medicolegal head, Western Cape Department of Health, personal communication November 2017). Whereas claims data are unavailable in the private sector, professional indemnity fees have risen most steeply for obstetricians and gynaecologists (O\&Gs). Over a 10-year period, rates for occurrence-based cover charged by the MPS have increased almost 10-fold, from ZAR109 240 in 2009 to ZAR1 150000 in 2019. This contrasts with premiums for practitioners whose practice is limited to gynaecology, including antenatal care up to $\sim 24$ weeks' gestation, which have increased $<4$-fold over the same period. Whereas in 2009 O\&Gs providing full obstetric services paid less than twice the amount of colleagues with a more limited practice (C Venter, Director, Healthman, personal communication October 2019), by 2019 the difference in these premiums was more than 5 -fold (data on file). 


\section{Objectives}

While public sector data and trends in professional indemnity premiums suggest that claims for cerebral palsy have been driving the burgeoning insurance burden of O\&Gs in the private sector, there are no empirical data to support this hypothesis. Implementation of effective controls of runaway litigation costs, including medical liability reform policies and quality improvement strategies, are furthermore hampered by lack of relevant data. ${ }^{[7,8]}$ To obtain a better understanding of the factors that may have contributed to the sharp increases in professional indemnity fees for O\&Gs in SA's private sector and provide a platform for further research and the design and prioritisation of practical solutions, the objective of this study was to analyse trends in medicolegal complaints against these practitioners and identify risk factors for patient dissatisfaction and medical negligence within the group.

\section{Methods \\ Study design}

This was a retrospective, observational study of current and historical medicolegal insurance notifications by O\&Gs in SA's private practice. Data were sourced from Constantia Insurance Company, a SA provider of medical professional indemnity cover.

\section{Measurements}

All medicolegal cases on file were dated and categorised in terms of insurance case type and clinical parameters. Incident date referred to the year in which an incident relating to a case occurred. Notification date was the year a doctor became aware of a medicolegal dispute or potential medicolegal dispute in relation to such a case and reported it to the insurer. Regarding case type, the most recent and relevant legal status of a case was defined, taking into consideration previous insurers' classification, personal updates from the practitioner shared during policy application, underwriting and claims management processes at Constantia, as well as case-related financial data, where available. Case types included summonses with or without paid settlements, letters of demand, requests for records, regulatory investigations, subpoenas, written complaints, inquests, notifications of circumstance and general requests for advice. In terms of clinical parameter coding, the main identifiable factor(s) underlying a complaint were defined by the clinical researcher using the best available information. These could include alleged or actual clinical error, unethical behaviour, clinical circumstance and/or suboptimal outcome. Associated procedure type was classified, where applicable. All cases were coded to indicate whether they were related to pregnancy (obstetrics), including antenatal, peripartum and postnatal care, as well as management of early miscarriages, ectopic pregnancies and terminations of pregnancy.

\section{Analysis}

Python Script, version 3.7.10 (Python Software Foundation, USA) was used to calculate annual medicolegal risk exposure on the basis of individual doctors' year of entry into private practice. This was used to estimate trends in relation to case incidence over time. A practitioner-driven database was furthermore generated which included non-identifiable practitioner-related demographic information, as well as years of risk exposure and count of cases per case type for a 10-year period from 2009 to 2018. This data source was used to assess medicolegal risk across practitioners. Only practitioners who had been in private practice for $>2$ years were included, to reduce underestimation of case incidence for recent entrants into private practice, given the time lag between a clinical incident and a subsequent medicolegal enquiry or demand.
To avoid potential duplication of cases and undue linking of irrelevant cases, some cases were excluded from the final analysis, for example investigations relating to claims against third parties such as the state or the Road Accident Fund. Descriptive analyses were generated in Excel, Microsoft Office 365 ProPlus (Microsoft, USA).

\section{Ethics approval}

Approval to conduct the research was granted by the Research Ethics Committee of the University of Cape Town. Confidentiality of practitioner-related information was safeguarded throughout the study. Only the primary investigator as an employee of Constantia Insurance had access to raw data.

\section{Results}

\section{Doctor demographic information}

Cases of 521 O\&Gs were reviewed, with demographic characteristics of these practitioners depicted in Table 1. For 2 doctors, demographic data were incomplete. Taking into consideration that there are an estimated 769 O\&Gs in private practice, ${ }^{[9]}$ this constitutes the medicolegal case histories of more than two-thirds of practitioners in this specialty group in the SA private sector.

\section{Case types}

Following removal of duplicate cases, and investigations and complaints against third parties such as the state, 1848 cases were considered for inclusion in various analyses. Of these, 1068 were associated with documented patient complaints, ranging from written complaints and enquiries by the Health Professions Council of South Africa and the Office of Health Standards Compliance to requests for records to investigate a potential claim, letters of demands and summonses. For the remaining 780, there was no evidence of patient dissatisfaction, with the majority being notifications of circumstance in the context of claims made as opposed to occurrence-based indemnity cover. These notifications are part of the reporting that the insurer requires doctors to make in order to secure indemnity cover should there be a future claim. While all reported patient complaints formed the basis for describing historical trends in terms

Table 1. Demographics of obstetricians and gynaecologists contributing medicolegal case histories to analyses $(N=521)^{*}$

\begin{tabular}{ll}
\hline Category and variable & $\boldsymbol{n}(\%)$ \\
\hline Gender & \\
Male & $308(59)$ \\
$\quad$ Female & $213(41)$ \\
Age (years) & \\
$\quad<45$ & $193(37)$ \\
$45-54$ & $147(28)$ \\
$55-64$ & $126(24)$ \\
$\geq 65$ & $54(10)$ \\
Years in private practice & \\
$\leq 2$ years & $63(12)$ \\
$>2-\leq 10$ & $177(34)$ \\
$>10$ & $281(54)$ \\
Province of practice & \\
Gauteng & $215(41)$ \\
$\quad$ Western Cape & $123(24)$ \\
KwaZulu-Natal & $80(15)$ \\
Other & $101(19)$ \\
*For 2 doctors, demographic data were incomplete. &
\end{tabular}


of the annual incidence of medicolegal cases, as well as clinical circumstances relating to settled claims, data subgroups limited to cases from 2009 and subsequent years were analysed to estimate the contribution of obstetric v. gynaecological cases and the contribution of individual O\&Gs to the medicolegal case burden among this group of specialists in the private sector more recently. The number of cases by case type and as included in the various analyses is summarised in Table 2.

\section{Annual case incidence trends}

There was evidence of a sharp increase in medicolegal investigations and complaints against O\&Gs providing services in the private sector from about 2003 to 2012. Since 2012, these activities have generally remained high (Fig. 1). The higher number of requests for records relative to demands in 2016 and 2017 compared with previous years is likely to reflect a delay in summons following a request for records,

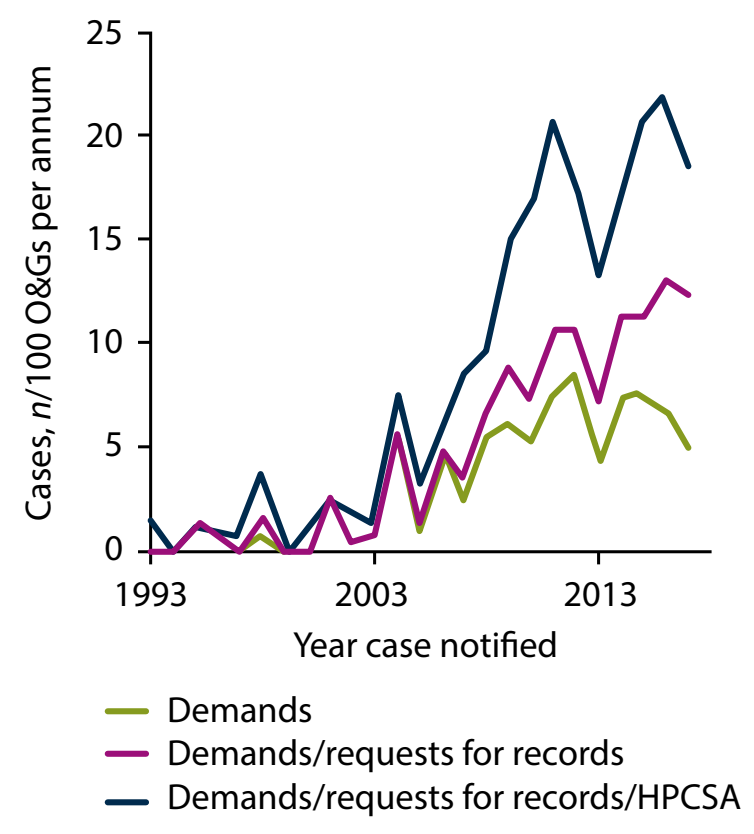

Fig. 1. Annual incidence of medicolegal investigations and complaints. (O\&Gs = obstetricians and gynaecologists; HPCSA = Health Professions Council of South Africa.) as well as lag in insurer update in this regard. The rate of increase in patient dissatisfaction following professional care rendered appeared similar for obstetrics and gynaecology. Fig. 2 represents annual trends of all O\&G complaints reported to the insurer. Pregnancy status was unknown in $24 \%$ of cases.

\section{Obstetrics v. gynaecology cases}

Whereas doctors were more concerned about the risk posed by obstetric cases, more gynaecology cases resulted in actual claims and settlements. For cases notified to the insurer during the 10.5-year study period between 2009 and 2019 and where associated pregnancy status could be identified, $59 \%$ were related to obstetrics. This ratio, however, switched where only patient demands with or without settlements were analysed, with $42 \%$ of demands accounted for by obstetrics. Most paid claims (76\%) were related to gynaecological problems. Pregnancy status was unknown for 10 settlements (18\%), 23 demands (9\%), 140 patient complaints associated with regulatory and/or legal engagement (19\%), 207 of all reported patient complaints (22\%), and 292 of all notifications (17\%). Fig. 3 represents

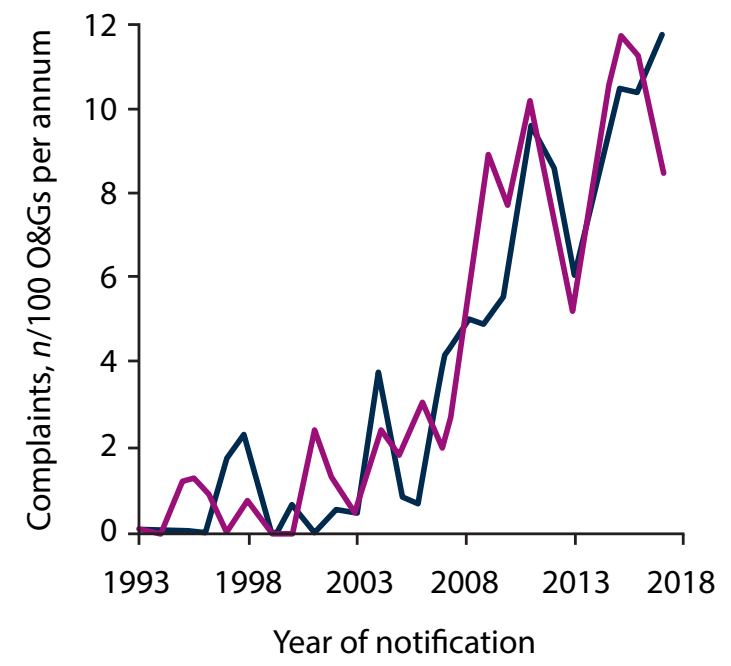

- Patient dissatisfaction, pregnancy related - Patient dissatisfaction, not pregnancy related

Fig. 2. Annual incidence of pregnancy- $v$. non-pregnancy-related patient complaints. (OßGs = obstetricians and gynaecologists.)

Table 2. Number of cases by case type included in the various analyses reported

\begin{tabular}{|c|c|c|c|c|c|}
\hline & \multicolumn{4}{|c|}{ Case type, $n$} & \multirow[b]{2}{*}{$\begin{array}{l}\text { O\&Gs } \\
\text { contributing } \\
\text { cases, } n\end{array}$} \\
\hline & $\begin{array}{l}\text { Demands } \\
\text { with known } \\
\text { settlements }\end{array}$ & Demands & $\begin{array}{l}\text { Cases with evidence of } \\
\text { legal and/or regulatory } \\
\text { engagement by the patient }\end{array}$ & $\begin{array}{l}\text { Cases with } \\
\text { evidence } \\
\text { of patient } \\
\text { dissatisfaction }\end{array}$ & \\
\hline $\begin{array}{l}\text { Total study population } \\
\text { All cases (patient complaints) for all O\&Gs }\end{array}$ & 86 & 305 & 845 & 1068 & 521 \\
\hline $\begin{array}{l}\text { Subgroup } 1 \\
\text { Cases from } 2009 \text { for all O\&Gs }\end{array}$ & 55 & 245 & 727 & 935 & 521 \\
\hline $\begin{array}{l}\text { Subgroup } 2 \\
\text { Cases from } 2009 \text { for O\&Gs in private practice } \\
>2 \text { years }\end{array}$ & 55 & 228 & 665 & 849 & 458 \\
\hline
\end{tabular}


the proportion of different medicolegal case types reported during the study between 2009 and 2019 that relate to obstetric as opposed to gynaecological care.

\section{Case aetiology}

Of 50 gynaecological cases settled, 46 (92\%) were procedure-related, of which $41 \%$ were a result of injuries to internal organs and vessels during surgery. Further injuries may have been included in the more generic category of postoperative complications that included postoperative haemorrhage, fistula formation and sepsis. Failed sterilisations accounted for $12 \%$ of all settlements.

Of the 19 obstetric cases settled, almost all emanated from the intrapartum and immediate postpartum period. About half

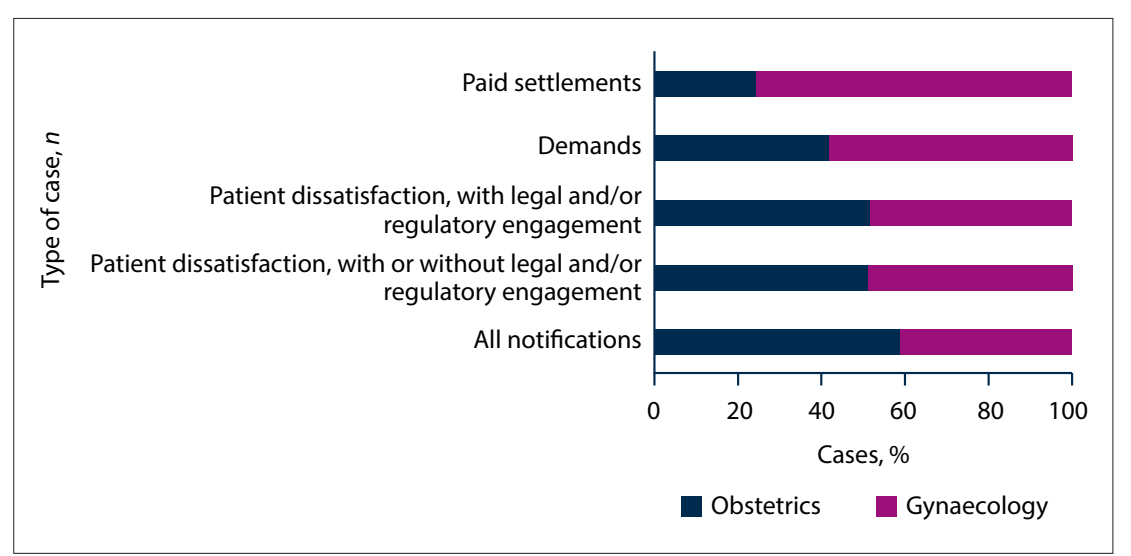

Fig. 3. Obstetrics- and gynaecology-related cases, 2009 - 2019. were for birth-related neonatal neurological injury. In terms of clinical outcome, $6 / 69$ cases $(9 \%)$ were related to maternal death or death of a gynaecological patient. No known settlements were associated with neonatal deaths. For 17 paid settlements ( $20 \%$ of cases), there was insufficient clinical information to make a reasonable assessment of clinical circumstances that led to a claim. Full details are shown in Tables 3 and 4 .

To gain further insights into the dominant drivers of claim burden as determined by case frequency, regulatory and legal investigations and demands over a 10.5 -year period starting in 2009 were interrogated.

\section{Intraoperative injuries to internal organs and vessels}

Given that at least $29 \%$ of settled cases related to major intraoperative injuries, all demands in this regard notified during the study period from 2009 to 2019 were further analysed in terms of associated procedure and injury types. Where surgical approach was listed, laparoscopy was identified in

\begin{tabular}{ll} 
Table 3. Aetiological factors associated with gynaecology-related paid claims & Cases, $n$ \\
\hline Case aetiology & 19 \\
\hline Procedure-related complications & 7 \\
Procedure-related injury, internal organs/vessels & 6 \\
Postoperative complications, including haemorrhage, sepsis and fistula formation & 4 \\
Failed and/or inadequate procedure & 3 \\
Retained surgical products/swabs & 3 \\
Surgical burns & 2 \\
Multifactorial/unknown & 1 \\
Mesh- and slings-related complication & 1 \\
Inadequate consent & 2 \\
Cosmetic dissatisfaction & 2 \\
Non-surgical complaints & 2 \\
Delayed and/or incorrect diagnosis & 50 \\
Incorrect prescriptions &
\end{tabular}

\section{Table 4. Aetiological factors associated with obstetrics-related paid claims}

\begin{tabular}{ll}
\hline Pregnancy period and case type & Cases, $n$ \\
\hline Antenatal & 2 \\
Missed fetal abnormality & 1 \\
Cervical cerclage removal & 9 \\
Peri- and postpartum & 1 \\
Birth hypoxia/severe neurological injury of the newborn & 1 \\
Suturing of third-degree perineal tear & 1 \\
Caesarean section, ureteric injury & 1 \\
Caesarean section, maternal death due to sepsis & 2 \\
Caesarean section, retained swab & 1 \\
Postpartum haemorrhage/retained products of conception with hysterectomy & 19 \\
Maternal death due to fibroid degeneration & 1
\end{tabular}


association with these injuries more frequently than open procedures. Bowel injury was the most common site of injury in cases litigated. Full details are shown in Table 5.

\section{Birth trauma resulting in severe neonatal neurological injury}

As the number of demands for birth-related trauma resulting in severe neurological injury of the newborn was low in absolute terms, requests for records were included in a subanalysis to identify claim trends in terms of this adverse outcome. Whereas no obvious trends of medicolegal activity over a 10-year period could be identified, 2017 was associated with an increased incidence of requests for records compared with previous years (Fig. 4). Late enquiries into births may have contributed to this finding (with one event notified as a result of a request for records 14 years and another 17 years previously). Whereas details regarding circumstances leading to alleged birth-related trauma were only available for a limited number of cases, the contribution of alleged hospital errors such as failure to monitor patients during labour, failure to report adverse cardiotocography readings to the responsible obstetrician, and/or failure to facilitate theatre access for the purposes of emergency caesarean section was evident in multiple cases. Other than hospital failures, problems with availability of anaesthetists during emergencies were cited in two recent cases.

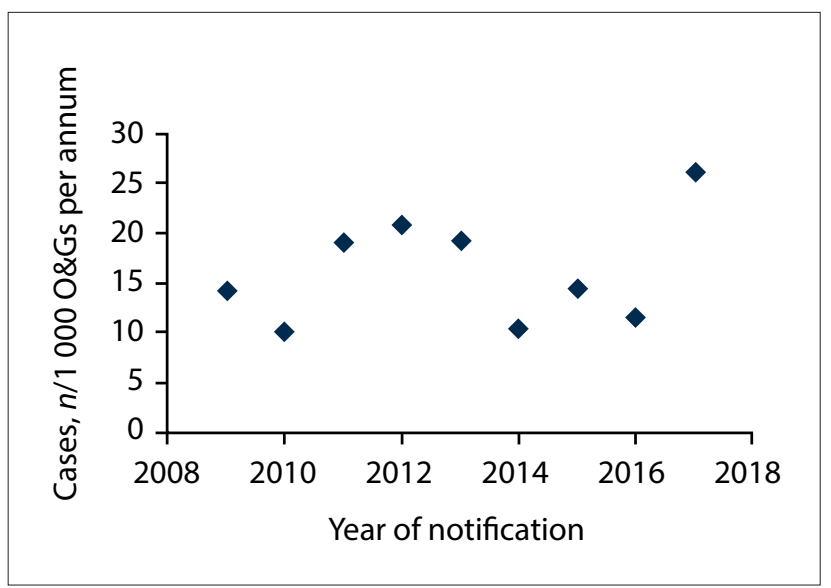

Fig. 4. Annual risk-adjusted incidence of requests for records and demands relating to severe birth-related neonatal neurological injuries. (O\&Gs = obstetricians and gynaecologists.)

\section{Distribution of medicolegal risk among O\&Gs}

To understand the contribution of individual practitioners to case burden, the average annual case rate over a 10 -year period for all practitioners who had been in practice for $>2$ years was calculated. Cases were defined as demands, regulatory investigations and requests for records. Where a demand was associated with a paid settlement, it was double counted. The average case rate per practitioner was estimated by dividing the weighted number of claims for a 10 -year period from 2009 by years of risk exposure as a specialist in private practice. Results are depicted in Fig. 5. Furthermore, 203/458 O\&Gs (44\%) had no cases reported. Of these, 149 had been in practice for at least 5 years and 89 for the full 10 -year period of the study. At the other end of the spectrum, 9 doctors were identified who reported at least one case per annum; 7 of these practitioners had been in practice for $\geq 8$ years. Another 2 had just started out in practice. During the study period, 50/458 (11\%) of O\&Gs accounted for 138/228 (61\%) of demands.

\section{Discussion}

The financial impact of medicolegal developments in SA is threatening the progressive realisation of universal health coverage. While government is looking to mobilise additional funds and human resources as part of its National Health Insurance scheme, burgeoning claims of medical negligence in the public sector are ironically usurping healthcare budgets earmarked for service delivery. In the private sector, exponential increases in professional indemnity fees are threatening the viability of professions such as $\mathrm{O} \& \mathrm{G}$. To stabilise the healthcare industry, diverse solutions ranging from reform of the medical malpractice litigation system and regulatory framework to clinical quality improvement programmes and new indemnity models need consideration.

The focus of this study was to support improvements in healthcare delivery as a basis for controlling litigation costs. Other than seeking compensation for actual losses, pain and suffering or the provision of future care, one of the reasons patients litigate is to prevent similar events in future. ${ }^{[10]}$ The legal system is therefore seen as a vehicle to hold the healthcare system accountable and in check. In the USA, where medical liability reform has been on the national agenda for an extended period, the debate regarding liability cost control has shifted to include patient safety improvement. Not only can medical liability reform impact on clinical practice and with that the quality and cost of care delivered to patients, but perceived errors in the

Table 5. Analysis of intraoperative injuries associated with claims from 2009 to 2019

\begin{tabular}{ll}
\hline Procedure & Known injury to internal organs and vessels (site of injury), $n$ \\
\hline Laparoscopic gynaecological procedure & 23 (12 bowel, 6 ureter, 2 bladder, 2 blood vessel, 1 unknown) \\
Abdominal/vaginal hysterectomies/oophorectomies & 15 (4 bowel, 6 bladder, 4 ureter, 1 unknown) \\
Hysterectomies/oophorectomies ${ }^{*}$ & 16 (4 bowel, 6 bladder, 5 ureter, 1 urethra) \\
Caesarean section & 11 (6 bowel, 2 bladder, 2 ureter, 1 other) \\
Sterilisation (known laparoscopic excluded) & 1 (unknown) \\
Sterilisation, laparoscopic & 1 (bowel) \\
D\&C/ToP & 1 (bowel) \\
Endometrial ablation & 1 (bowel) \\
Hysteroscopy & 2 (bowel) \\
Contraception & 1 (uterine and bowel perforation due to hormonal intrauterine device) \\
Unspecified/other procedures ${ }^{\star}$ & 2 (1 bowel, 1 ureter) \\
Total & 74 \\
&
\end{tabular}




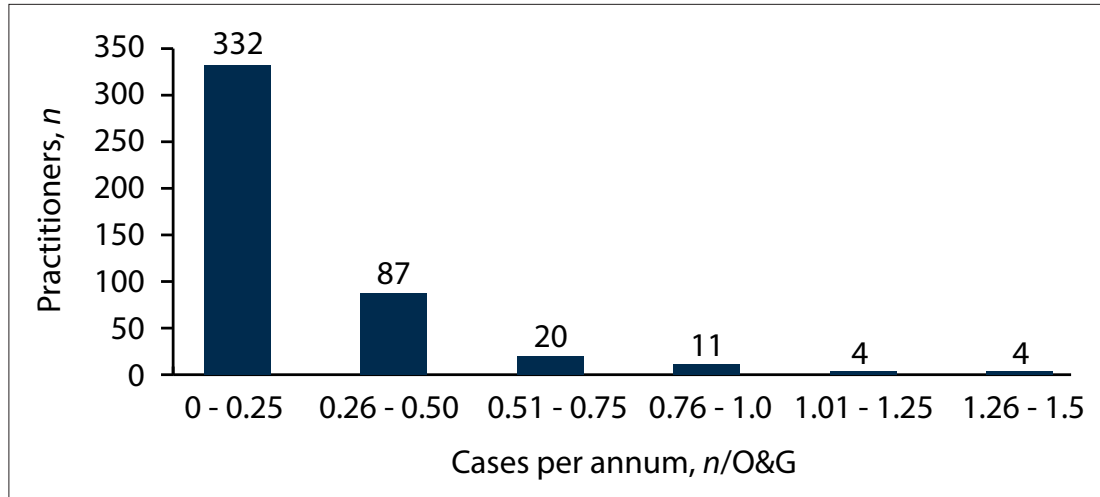

Fig. 5. Average annual incidence of summons, requests for records and HPCSA complaints for duration in private practice per O\&G. $(O \& G=$ obstetrician and gynaecologist; HPCSA $=$ Health Professions Council of South Africa.)

delivery of healthcare are at the core of the medicolegal challenge. ${ }^{[1]]}$ Furthermore, cases that are litigated are said to make up 'the tip of the iceberg' of clinical errors. Based on studies in the USA, it has been estimated that only $2-3 \%$ of patients injured by negligence file claims. The need for a sound understanding of 'where things go wrong' in the healthcare delivery system is therefore important for the purposes of designing and prioritising effective interventions aimed at the primary prevention of litigation. Whereas wrong actions by individuals such as 'slips, lapses, fumbles, mistakes and procedural violations' underpin errors, prevention of future incidents of a similar nature necessitates an understanding of weaknesses in the system that provoked or failed to prevent such incidents, together with the implementation of corrective measures. ${ }^{[12]}$ As maintained by Reason, ${ }^{[12]}$ the majority of adverse events involve a combination of 'active failures' and 'latent conditions'. Latent conditions, also referred to as 'resident pathogens' within the system, reflect decisions made by policymakers and top-level management that define the context within which healthcare practitioners offer their services. In terms of errors on the ground, Kravitz et al. ${ }^{[13]}$ differentiate between patient management problems, technical performance inadequacies and failures of teamwork as a result of poor communication between members of the medical and nursing teams. Medicolegal data are being harnessed in various parts of the world to assist with the identification of medicolegal risks and associated opportunities for risk interventions. ${ }^{[14-19]}$

Following this first empirical research investigating claims against $\mathrm{O} \& \mathrm{Gs}$ in SA's private sector, the relatively high number of demands and settlements for gynaecology- v. obstetrics-related care was unexpected.
Contrary to experiences reported from other countries, gynaecological rather than obstetric care appears to have been driving the claim burden from the perspective of claim frequency. In Saudi Arabia, 80.7\% of claims were related to obstetrics, with higher ruling in favour of the plaintiff in $61 \%$ of cases, as opposed to $18 \%$ in gynaecology. ${ }^{[17]}$ In Spain, $61.9 \%$ of O\&G claims involved obstetrics. ${ }^{[18]}$ Twice as many claims were received for obstetric as opposed to gynaecological care by the National Health Service in the UK in 2016/2017 $\left(10 \%\right.$ v. $5 \%$ of all claims received). ${ }^{[20]} \mathrm{A}$ review of medical malpractice cases on file in the Forensic Association in Turkey indicated that $96 \%$ of O\&G claims were in the context of obstetrics v. $4 \%$ for gynaecology ${ }^{[21]}$ In SA's public system, at least $76 \%$ of O\&G claims are related to obstetrics. Whereas direct comparison of obstetrics v. gynaecology risk across countries is difficult owing to lack of a common definition, gynaecology cases in this study were classified in their narrowest sense. For example, therapeutic abortions were classified in the obstetric category. ${ }^{[13,21]}$ We may therefore have slightly underestimated the proportion of gynaecological claims, suggesting that the divergence in our findings v. other countries may be more pronounced than described here.

Cerebral palsy is a dominant driver of medicolegal costs in many healthcare systems. ${ }^{[18,20]}$ Other than being associated with high quanta of demands, severe neurological deficit as a result of alleged neonatal birth injury was also the most frequent context of settled obstetrics-related claims in this study. While the contribution of system failures could not be quantified adequately, clear problems in this regard were documented, including failure to monitor fetal wellbeing during labour, failure to report fetal distress to the attending obstetrician, and lack of availability of theatre staff and/or anaesthetist. Based on a recent analysis of 200 SA public sector claims where intrapartum care was deemed to be substandard, failure to monitor fetal distress was evident as the main aetiological factor in $43 \%$ of cases and failure to respond to fetal distress in another 26\% (Buchmann E, 'Normal labour', presented at a 2019 symposium on 'Medical litigation and cerebral palsy - understanding the medical complexities', Janilite Pty Ltd and Norton Rose Fulbright). Errors with fetal heart monitoring were also recognised as the dominant theme among cerebral palsy claims abroad. ${ }^{[20,22]}$

In terms of gynaecological care, the high proportion of claims and settlements relating to gynaecological surgery, especially injury to internal organs during laparoscopic procedures, but also during open surgery, raises questions. Concerns relating to this finding are particularly relevant taking into consideration a recent report by the South African Society of Surgeons in Training (SASSiT) that many registrars feel ill-prepared for independent practice, particularly in the field of minimally invasive surgery. ${ }^{[23]}$ The need for training to be reviewed in the context of laparoscopic surgery has also been identified in other parts of the world. ${ }^{[24,25]}$ One of the key recommendations in this regard has been the integration of simulator training and standardised assessments prior to real-time operating-room experience into national curricula and board certification processes. Whereas technical dexterity is important for any surgeon, specific psychomotor skills are required for the safe and effective performance of laparoscopically guided procedures. Remote handling of instruments without tactile feedback, two-dimensional depth perception and fine motor skills in relation to the use of long instruments and the fulcrum effect - which refers to tool endpoints moving in the opposite direction to the surgeon's hands - are skills that make these procedures particularly challenging. Only those whose skills have been validated in vitro should be able to proceed with operations on patients and qualify for certification. In a study analysing 133 laparoscopy-related gynaecology claims over a 20-year period, visceral and vascular injuries accounted for $82 \%$ of these. More than three-quarters $(77 \%)$ related to basic rather than advanced laparoscopic procedures such as diagnostic laparoscopy, tubal ligations and salpingo-oophorectomies, supporting the need for a basic skill set even for the simpler procedures. ${ }^{[26]}$ 
The unequal distribution of medicolegal risk among practitioners has been described by others. ${ }^{[27-29]}$ Based on the findings of this study, any $O \& G$ in private practice who on average has one or more requests for records, regulatory complaints or claims in any 2-year period should reflect on and address potential contributing factors that may include ways of communication, accessibility, technical standards of work and attitude to patient complaints, as well as environmental influencers. Contrary to some practitioners' beliefs, not only paid but also unpaid claims have predictive value in terms of future demands. ${ }^{[30]}$

\section{Study limitations}

While the study was based on real-life data, every effort was made to correct inadvertent data inaccuracies and gaps by correlating previous insurers' case histories with self-reported incidents by doctors. With case types not categorised in a standardised manner across the industry, some cases had to be reclassified using best available evidence. In addition, information on incident dates was limited, so analyses had to rely on notification dates. Potential differences in time intervals between adverse incidents and subsequent claims against the practitioner for gynaecology- v. obstetrics-related care with obstetric claims more commonly delayed beyond 3 years following an adverse event - may have slightly skewed the results of some of the time-based analyses. Where year of entry into private practice by practitioners was unknown, an assumption was made that it had occurred the year after registration as a specialist, leading to potential over-estimation of a practitioner's number of years in private practice. Overall, the potential limitations are unlikely to have influenced the validity of key findings in a meaningful way.

\section{Conclusions}

In contrast to other countries that have experienced steep increases in medicolegal demands, empirical data depicting private sector $O \& G$ medicolegal trends and analysing these to guide and lobby solutions have been scarce in SA to date. Whereas multidimensional reform that spans across the healthcare, litigation and insurance systems is required to address the impact of medicolegal trends on obstetricians, this study was aimed specifically at understanding factors within clinical practice itself that may be predisposing to claims against practitioners, as a basis for defining and prioritising quality improvement solutions. Taking into consideration relative increases in professional indemnity fees for $O \& G$ over recent years, as well as international experiences, the high frequency of settled claims relating to gynaecological procedures was unexpected. Reasons for this should be explored and should include an analysis of surgical complications for main procedure types in the private sector. Review of aspects of surgical training and accreditation standards in O\&G may also be called for, together with the consideration for surgical mentorship programmes. In terms of claims relating to severe birth trauma, more research is required to understand and quantify system failures that may be contributing to medicolegal risks in this regard in the private sector and the impact of these on obstetric practice. The high concentration of medicolegal complaints among a small group of practitioners furthermore highlights the need for doctor-focused solutions, including strengthening of peer review and regulatory oversight.

Declaration. The research for this study was done in partial fulfilment of the requirements for BT's MPH (Health Economics) degree at the University of Cape Town.

Acknowledgements. We would like to acknowledge the following people and organisations that have assisted over the course of this study:
Constantia Insurance Company Limited for enabling data collation and access, and Stefan Strydom (MastAnalytics) and Nicolas Taylor (BSc student) for data management support.

Author contributions. BT: conceptualisation, design, analysis, interpretation of data; SC: critical revision.

Funding. None.

Conflicts of interest. BT is an employee of Constantia Insurance Company Limited.

1. Australian Medical Association. How the crisis unfolded. AMA (New South Wales). https://www amansw.com.au/how-the-crisis-unfolded/ (accessed 25 November 2019).

2. Chen KY, Yang CM, Tsai SH, Chiou HY, Lin MR, Chiu WT. Medical malpractice in Taiwan: Injury types compensation, and specialty risk. Acad Emerg Med 2012;19(5):598-600. https://doi.org/10.1111/j.15532712.2012.01360.x

3. Li H, Wu X, Sun T, et al. Claims, liabilities, injuries and compensation payments of medical malpractice litigation cases in China from 1998 to 2011. BMC Health Serv Res 2014;14:390. https://doi. org/10.1186/1472-6963-14-390

4. Bateman C. NHI Bill set to worsen SA's medico-legal nightmare - experts. Medical Brief, 18 September 2019. https://www.medicalbrief.co.za/archives/nhi-bill-set-to-worsen-sas-medico-legal-nightmareexperts/ (accessed 25 November 2019).

5. experts/ (accessed 25 November 2019). Howarth G, Hallinan E. Challenging the cost of
https://doi.org/10.7196/SAMJ.2016.v106i2.10408

McCaffrey S. Medical Protection Society. Challenging the cost of clinical negligence. Casebook 2015;23(2):7. https://www.medicalprotection.org/docs/default-source/pdfs/casebook-pdfs/south-africacasebook-pdfs/southafrica_casebook_web.pdf (accessed 30 May 2021).

7. South African Law Reform Commission. Project 141 - Medico-legal claims. Issue Paper, 20 May 2017. http://www.justice.gov.za/salrc/ipapers/ip33_prj141_Medico-legal.pdf (accessed 14 October 2019).

Oosthuizen WT, Carstens PA. Medical malpractice: The extent, consequences and causes of the problem. J Contemp Roman-Dutch Law 2015;78:269-284. https://ssrn.com/abstract=2693960 (accessed 25 May 2021). Wishnia J, Strugnell D, Smith AM, Ranchod S. The Supply of and Need for Medical Specialists in South Africa. Cape Town: Percept, 2019.

10. Jha S, Rowland S. Litigation in gynaecology. Obstetrician Gynaecologist 2014;16(1):51-57. https://doi org/10.1111/tog.12065

1. Kachalia A, Mello MM. New directions in medical liability reform. N Engl J Med 2011;364(16):15641572. https://doi.org/10.1056/NEJMhpr1012821

2. Reason J. Human error: Models and management. BMJ 2000;320(7237):768-770. https://doi.org/10.1136 bmj. 320.7237 .768

3. Kravitz RL, Rolph JE, McGuigan K. Malpractice claims data as a quality improvement tool Epidemiology of error in four specialties. JAMA 1991;266(15):2087-2092. https://doi.org/10.1001/ jama.1991.03470150059031

4. National Practitioner Data Bank, US Department of Health and Human Services. https://www.npdb. hrsa.gov/topNavigation/aboutUs.jsp (accessed 27 November 2019).

5. Medical Professional Liability Association. Data Sharing Project. MPL, 2019. https://www.mplassociation. org/data-sharing-project (accessed 30 May 2021).

6. Pegalis SE, Bal BS. Closed medical negligence claims can drive patient safety and reduce litigation. Clin Orthop Relat Res 2012;470(5):1398-1404. https://doi.org/10.1007/s11999-012-2308-5

17. AlDakhil LO. Obstetric and gynecologic malpractice claims in Saudi Arabia: Incidence and cause. J Forensic Leg Med 2016;40(May):8-11. https://doi.org/10.1016/j.jflm.2016.02.001

18. Gomez-Duran EL, Mula-Rosías JA, Lailla-Vicens JM, Benet-Trave J, Arimany-Manso J. Analysis of obstetrics and gynecology professional liability claims in Catalonia, Spain (1986 - 2010). J Forensic Leg Med 2013:20(5):442-446. https://doi.org/10.1016/j.jflm.2012.12.006

19. Spittal MJ, Bismark MM, Studdert DM. The PRONE score: An algorithm for predicting doctors' risks of formal patient complaints using routinely collected administrative data. BMJ Qual Saf 2015;24(6):360368. https://doi.org/10.1136/bmjqs-2014-003834

20. Magro M. Five years of cerebral palsy claims - a thematic review of NHS Resolution data. NHS Resolution, September 2017. https://resolution.nhs.uk/wp-content/uploads/2017/09/Five-years-ofcerebral-palsy-claims_A-thematic-review-of-NHS-Resolution-data.pdf (accessed 5 November 2019).

1. Büken E, Büken NÖ, Büken O. Obstetric and gynecologic malpractice in Turkey: Incidence, impact, causes and prevention. J Clin Forensic Med 2004;11(5):233-247. https://doi.org/10.1016/j. jcfm.2004.01.005

22. Berglund S, Grunewald C, Pettersson H, Cnattingius S. Severe asphyxia due to delivery-related malpractice in Sweden 1990 - 2005. BJOG 2008;115(3):316-323. https://doi.org/10.1111/j.1471 0528.2007.01602.x

23. Patel N, Leusink A, Singh N, Koto MZ, Luvhengo T. Registrar perceptions on general surgical training in South Africa: A report by the South African Society of Surgeons in Training (SASSiT). S Afr J Sur 2018;56(2):10-14. https://doi.org/10.17159/2078-5151/2018/v56n2a2448

24. Campo R, Puga M, Meier Furst R, Wattiez A, de Wilde RL. Excellence needs training 'Certified progamme in endoscopic surgery. Facts Views Vis Obgyn 2014;6(4):240-244. https://europeanacademy. org/files/2018/06/2014_Excellence-needs-training.pdf (accessed 28 November 2019).

25. Shore EM, Lefebvre GG, Grantcharov TP. Gynecology resident laparoscopy training: Present and future. Am J Obst Gyn 2015;212(3):298-301. https://doi.org/10.1016/.ajog.2014.07.039

26. Sandberg EM, Bordewijk EM, Klemann D, Driessen SRC, Twijnstra ARH, Jansen FW. Medical malpractice claims in laparoscopic gynecologic surgery: A Dutch overview of 20 years. Surg Endosc 2017;31(12):5418-5426. https://doi.org/10.1007/s00464-017-5624-8

27. Studdert DM, Bismark MM, Mello MM, Singh H, Spittal MJ. Prevalence and characteristics of physicians prone to malpractice claims. N Engl J Med 2016;374:354-362. https://doi.org/10.1056/NEJMsa1506137

28. Gomez-Duran EL, Martin-Fumado C, Benet-Trave J, Arimany-Manso J. Malpractice risk at the physician level: C

29. Bismark MM, Spittal MJ, Gurrin LC, Ward M, Studdert DM. Identification of doctors at risk of recurrent complaints: A national study of healthcare complaints in Australia. BMJ Qual Saf 2013;22(7):532-540. complaints: A national study of healthcare comp
https://doi.org/10.1136/bmjqs-2012-001691

30. Bovbjerg RR, Petronis KR. The relationship between physicians' malpractice claims history and later Bovbjerg RR, Petronis KR. The relationship between physicians' malpractice claims history and later
claims: Does the past predict the future? JAMA 1994;272(18):1421-1426. https://doi.org/10.1001/ claims: Does the past pred
jama.1994.03520180045033

Accepted 25 January 2021. 